\title{
Molecular characteristics of Bombus (Alpinobombus) polaris from North Greenland with comments on its general biology and phylogeography
}

\author{
Saeed Mohamadzade Namin ${ }^{1,2} \cdot$ Tae-Yoon Park ${ }^{3,4} \cdot$ Chuleui Jung $^{1,5} \cdot$ Victor Benno Meyer-Rochow ${ }^{1,6}(\mathbb{D}$
}

Received: 28 July 2021 / Revised: 28 September 2021 / Accepted: 29 September 2021 / Published online: 16 October 2021

(C) The Author(s) 2021

\begin{abstract}
The bumble bee Bombus polaris (Curtis 1835) is known from the northernmost region of Greenland. But how it can survive there, where in terms of geographic origin it came from, and which species in addition to B. pyrrhopygus (Friese 1902) genetically it is most closely related to are insufficiently answered questions that have motivated us to carry out this study. On the basis of a molecular analysis of the cytochrome oxidase I gene of a B. (Alpinobombus) polaris from North Greenland $\left(82^{\circ}\right.$ $48^{\prime} \mathrm{N} ; 42^{\circ} 14^{\prime} \mathrm{W}$ ), we conclude that the female specimen we analysed was most closely related to the Canadian populations of B. polaris. Geographic proximity, occurrence of B. polaris on Ellesmere Island and wind direction are likely factors that have aided B. polaris to establish itself in northern and eastern Greenland. The presence of five haplotypes in the studied sequences from Greenland indicates a moderately high level of genetic diversity of $B$. polaris in Greenland, reflecting the successful adaptation of $B$. polaris populations. In the broader context of entomological life in the high Arctic, our results on $B$. polaris allow us to conclude that the survival of pollinating species in the high Arctic under the changing climate scenario depends not only on the weather but also on an individual's opportunity to continue to locate suitable food sources, i.e. pollen and nectar in the case of $B$. polaris. This aspect, briefly touched upon in this study, is of relevance not just to $B$. polaris, but the Arctic entomofauna generally.
\end{abstract}

Keywords Arctic pollinator $\cdot$ Polar insects $\cdot$ DNA extraction and sequencing $\cdot$ Haplotypes $\cdot$ Population relationships

Victor Benno Meyer-Rochow meyrow@gmail.com

1 Department of Plant Medicals, Andong National University, Andong 36729, Republic of Korea

2 Department of Plant Protection, College of Agriculture, Varamin-Pishva Branch, Islamic Azad University, Varamin 3381774895, Iran

3 Division of Earth-System Sciences, Korea Polar Research Institute, 26 Songdomirae-ro, Yeonsu-gu, Incheon 21990, Republic of Korea

4 Polar Science, University of Science and Technology, Daejeon 34113, Republic of Korea

5 Agriculture Science and Technology Research Institute, Andong National University, Andong, Gyeongsangbuk 36729, Republic of Korea

6 Department of Ecology and Genetics, Oulu University, 90140 Oulu, Finland

\section{Introduction}

Bumble bees are important pollinators (Wahengam et al. 2019; Parrey et al. 2021) and famous for their cold hardiness (Couvillon et al. 2010). Thus, they have to be considered a crucial factor in the pollination ecology of flowering plants in the polar region. Alpinobombus is a monophyletic group of bumble bees distributed in the Arctic, alpine tundra and sub-Arctic area (Potapov et al. 2014; Williams et al. 2019). Recently, the classification of Alpinobombus has been studied in detail by different authors (e.g. Williams et al. 2015, 2019; Potapov et al. 2019). Based on morphological and molecular characterizations, the presence of at least eight species in this subgenus, namely Bombus alpinus (Linnaeus 1758), B. pyrrhopygus (Friese 1902), B. polaris (Curtis 1835), B. balteatus (Dahlbom 1832), B. kirbiellus (Curtis 1835), B. neoboreus (Sladen 1919), B. kluanensis (Williams and Cannings 2016) and B. hyperboreus (Schönherr 1809), has been suggested. However, there is some disagreement regarding the taxonomic position of $B$. hyperboreus natvigi having been raised to species level by Williams et al. (2015, 
2019) but seen as a geographic race within the B. hyperboreus complex by Potapov (2019). Of all the species of the subgenus Alpinobombus, only two, B. polaris and B. hyperboreus natvigi, are currently known to occur in Greenland (Potapov et al. 2019; Williams et al. 2019).

Species considered "true Arctic forms" by Potapov et al. (2014) included B. polaris, B. balteatus, B. hyperboreus and B. lapponicus glacialis (Fabricius 1793), the latter being elevated to species status B. glacialis by Potapov et al. (2018a). Some species like B. (Pyrobombus) glacialis glacialis now appear to have a somewhat restricted distribution, but in the past apparently occurred much more widely (Potapov et al. 2021). Other species, even today, are distributed over vast areas and, in the case of B. polaris, which is known from Alaska, the Canadian Arctic and Greenland, can be considered at least semi-circumboreal (Richards 1973; Vilhelmsen 2015). Until the review of the subgenus Alpinobombus by Williams et al. (2015), in which B. polaris was divided into two taxa, namely B. polaris sensu stricto in North America and Greenland and B. pyrrhopygus in coastal northern Eurasia, the latter was treated as a member of $B$. polaris (Rasmont and Iserbyt 2010-2014; Williams et al. 2015).

Although there are numerous other species of bumble bee occurring in sub-Arctic and temperate environments of the northern hemisphere (Kolosova et al. 2016; Martinet et al. 2018; Sheffield et al. 2020), including Iceland (Potapov et al. 2018b), it is the true Arctic species for which the smallest amount of biological, distributional and molecular data are available. The conservation status of many of the Arctic bumblebees is not completely clear (Hatfield et al. 2016) due to low population size, shortage of sampling season in the Arctic and small number of specialists focusing on the Arctic species. Therefore, observations on even a single specimen from a remote locality have to be seen as a welcome piece of information in the puzzle of the genetic diversity, phylogeography and evolution of this northernmost group of bumble bees.

Owing to their relatively large size and deep buzz during flight, Arctic bumble bees are spectacular insects. However, despite their huge geographic ranges over which they are known to occur and their undoubtedly important role as pollinators and members of the Arctic ecosystem (Kevan 1972), bumble bees are frequently ignored or, if mentioned at all, referred to only in passing in ecological texts and treatises of the Arctic (Born and Böcher 2001; Thomas 2021). Part of the reason is almost certainly the fact that nowhere in the Arctic, these hymenopteran insects are very common and abundant and thorough searches often yield no more than one or two specimens per location (e.g. Table 2: Potapov et al. 2019).

In regard to Arctic regions north of latitude $80^{\circ} \mathrm{N}$, only three species have ever been recorded: $B$. polaris, $B$. kirbiellus and B. hyperboreus natvigi. To what extent the molecular data of a female specimen of B. polaris from North Greenland that we had access to would match those of specimens from other localities in the Arctic was one of the objectives of this study and it was hoped that the results would also allow us to suggest from where the population of B. polaris in the north of Greenland could have originated. Other aspects were to examine if our data could help to shed light on the genetic variation and phylogenetic relationships between haplotypes of $B$. polaris to add information on how such bees survive in the high Arctic only $800 \mathrm{~km}$ south of the North Pole (equivalent to the distances between Paris and Marseille or Helsinki and Rovaniemi).

\section{Materials and methods}

The single female specimen we had a chance to work with stemmed from North Greenland ( $\left.82^{\circ} 48^{\prime} \mathrm{N} ; 42^{\circ} 14^{\prime} \mathrm{W}\right)$. It was caught on 19 July 2018 at $18.00 \mathrm{~h}$ by Dr Won Young Lee with a hand net in the vicinity of the Korean-Danish campsite at a location known as "Sirius Passet" whilst he was collecting wolf faeces for subsequent scat analyses. The land was covered by green plants, such as Saxifraga oppositifolia (Linnaeus 1758) and Dryas octopetala (Linnaeus 1758), and was part of a valley where strong wind can blow away the snow and expose the vegetation.

Although the highest temperature of the day of sampling was only $9.1{ }^{\circ} \mathrm{C}$, summer season temperatures at Sirius Passet frequently reach highs close to $16^{\circ} \mathrm{C}$ (Fig. 1). The specimen was carefully air-dried, taken to the "Korea Polar Research Institute" in Incheon (Republic of Korea) and subjected to molecular analysis at Andong National University (Republic of Korea). The dry specimen had a total body length of approximately $15 \mathrm{~mm}$ and according to the photographs (Fig. 2) given in Vilhelmsen (2015) and taken by Gert Brovad, it was identified as a B. polaris (Curtis 1835) queen (workers are never that large and males have a different body shape: Fig. 2). Although B. hyperboreus and $B$. polaris can be confused with each other (Vilhelmsen 2015), like many bumble bee species can, morphological characters using keys given in Williams et al. (2019) allowed us to identify the specimen quite reliably. Our identification was confirmed by comparing the COI sequence with the other published sequences of $B$. polaris available in GenBank (NCBI, https://www.ncbi.nim.nih.gov/).

\section{DNA extraction, primer, PCR and sequencing}

Total DNA was extracted using DNeasy Blood and Tissue kit (Qiagen, Seoul, Korea). A right front leg of the specimen was used for DNA extraction. A DNA barcoding region of the mitochondrial COI gene was amplified by the polymerase chain reaction (PCR) using AccuPower 


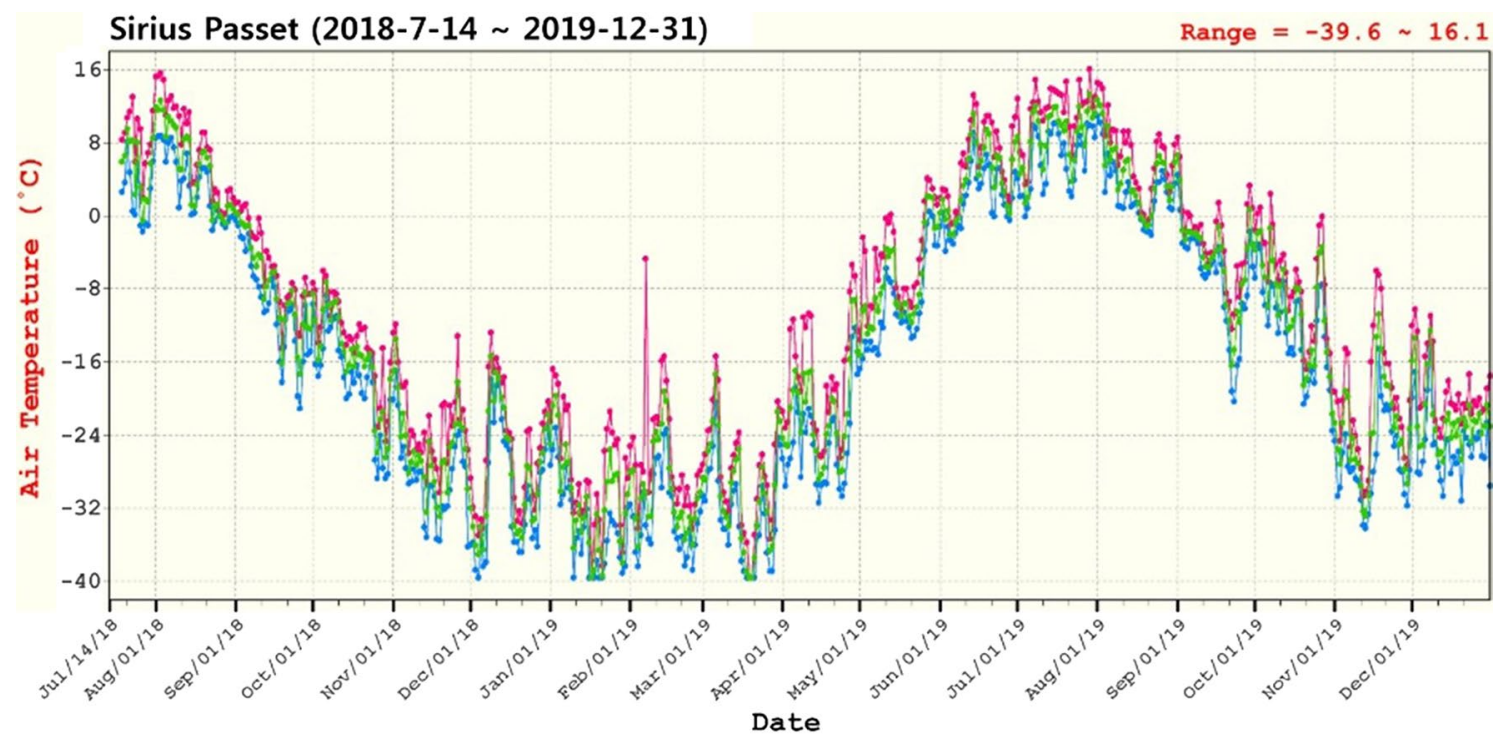

Fig. 1 Temperature extremes at "Sirius Passet" (North Greenland: $82^{\circ} 48^{\prime} \mathrm{N} ; 42^{\circ} 14^{\prime} \mathrm{W}$ ), where the female specimen of Bombus polaris was caught on 19 July 2018. Colour code: red =daily temperature maxima; blue =daily temperature minima; green =daily temperature averages

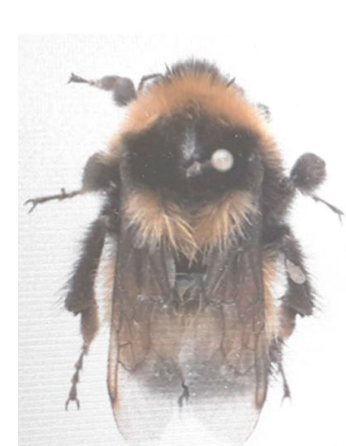

(a)

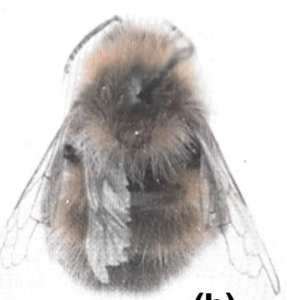

(b)

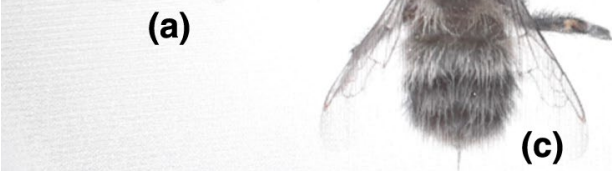

Fig. 2 Close-up photographs of preserved specimens of Bombus polaris Curtis 1835: queen (a); drone (b); worker (c). Reproduced by permission from Vilhelmsen (2015)

PCR PreMix (Bioneer, Daejeon, Korea) with the primer set LCO-1490 (5-GGTCAACAAATCATAAAGATATTG G-3) and HCO2198 (5-TAAACTTCAGGGTGACCAAAA AATCA-3) (Folmer et al. 1994). Amplifications were conducted with $5 \mathrm{~min}$ initial denaturation at $95{ }^{\circ} \mathrm{C}$ followed by 35 cycles of $30 \mathrm{~s}$ denaturation at $95^{\circ} \mathrm{C}, 30 \mathrm{~s}$ annealing at $52{ }^{\circ} \mathrm{C}$, a $1 \mathrm{~min}$ extension at $72{ }^{\circ} \mathrm{C}$ and a final extension for $5 \mathrm{~min}$ at $72{ }^{\circ} \mathrm{C}$. Sequencing was performed in both directions by Macrogen (Seoul, South Korea). The COI sequence data obtained in this study were deposited in GenBank databases under accession MN022986 and the

voucher specimen is deposited in the insect collection of Andong National University, Republic of Korea.

\section{Phylogenetic analysis and network construction}

Sequence reads were edited and assembled, using the Bioedit v7.0.5.2 (Hall 1999). Fifty-four previously reported B. polaris $\mathrm{COI}$ sequences were retrieved from NCBI database and were incorporated in the analysis (Online Resource No 1). The sequences were aligned, using Clustal $\mathrm{X}$ version 1.8 (Thompson et al. 1994). The jModelTest (version 2.1.3) programme was used to select the best nucleotide substitution model using the default parameters (Darriba et al. 2012). Bayesian analyses were conducted in MrBayes 3.1.2 (Huelsenbeck and Ronquist 2011), using the HKY mutation model. The analyses were performed for $2 \times 10^{6}$ generations at a temperature of $0.1^{\circ} \mathrm{C}$, with four chains each. Trees were sampled every 500 generations with $20 \%$ burn-in. Analyses were considered convergent when the average standard deviation of split frequencies was $<0.01$. B. pyrrhopygus, a sister taxon of B. polaris (Williams et al. $2015,2019)$, was used as an outgroup. The number of haplotypes was defined using DNAsp v5 (Librado and Rozas 2009) and a haplotype network was constructed using the medianjoining method (Bandelt et al. 1999) in Network software version 10 to infer the relationships amongst haplotypes and their geographical distribution. 


\section{Results}

\section{Genetic distance of the populations of B. polaris}

A total of 55 COI sequences of B. polaris from three countries (Canada, Greenland and USA) were analysed. In total, 14 haplotypes were obtained from 654-bp part of COI gene. Amongst countries, the pairwise genetic distance of $B$. polaris in the USA $(0.31-0.61 \%)$ was higher than that for Canada and Greenland where the genetic distances of haplotypes were $0.15-0.46 \%$ and $0.15-0.31$, respectively. On the other hand, the genetic distance between sequences from Canada and the USA was $0-0.6 \%$, whilst the genetic distances between haplotypes from Greenland with Canada and the USA were $0-0.8 \%$ and $0.15-1.07 \%$, respectively. The haplotype analyses revealed five haplotypes in Greenland $(N=17)$, eight haplotypes in Canada $(N=29)$ and three haplotypes in the USA $(N=8)$. Haplotype $\mathrm{H} 1$ was shared between Canada and the USA, whereas H5 was shared between Canada and Greenland. Distribution of four haplotypes was restricted to Greenland. Six haplotypes were only encountered in Canada, whereas the number of haplotypes restricted to the USA samples was two.

\section{Phylogenetic analysis and network construction}

A phylogenetic analysis was conducted to determine the relationships between available haplotypes of $B$. polaris from different regions. The results confirmed the monophyly of B. polaris with high support $(\mathrm{PP}=1)$. All Greenland haplotypes except H5 (shared between Canada and Greenland) clustered together in one subclade $(\mathrm{PP}=0.68)$ and two Canadian haplotypes clustered together with high posterior probability $(\mathrm{PP}=0.98)$, but the relationship between other haplotypes from Canada and the USA remained unresolved (Fig. 3).

The unrooted haplotype network demonstrated that Canadian and Greenland populations of B. polaris were genetically close to each other and the COI sequence of the newly collected sample from North Greenland was identical to H5 from Nunavut, Canada. According to the wide distribution of $B$. polaris in Canada and availability of representative sequences from different localities, the frequencies of sequences in different territories were also studied. Only a single haplotype was found from the Canadian Northwest (H12) and Yukon territories (H1) due to the lack of studied sequences. Most of the Canadian haplotypes exhibited a star-like topology with short branch lengths showing that the Canadian haplotypes were closely related to the common central haplotype (H1). Similarly, all haplotypes from
Fig. 3 Bayesian haplotypes phylogenetic tree of COI gene of Bombus polaris. Numbers on branches are Bayesian posterior probabilities. B. pyrrhopygus is used as an outgroup. $C A$ Canada, GL Greenland, $M a$ Manitoba, $N u$ Nunavut, $N W$ Northwest, $Y u$ Yukon

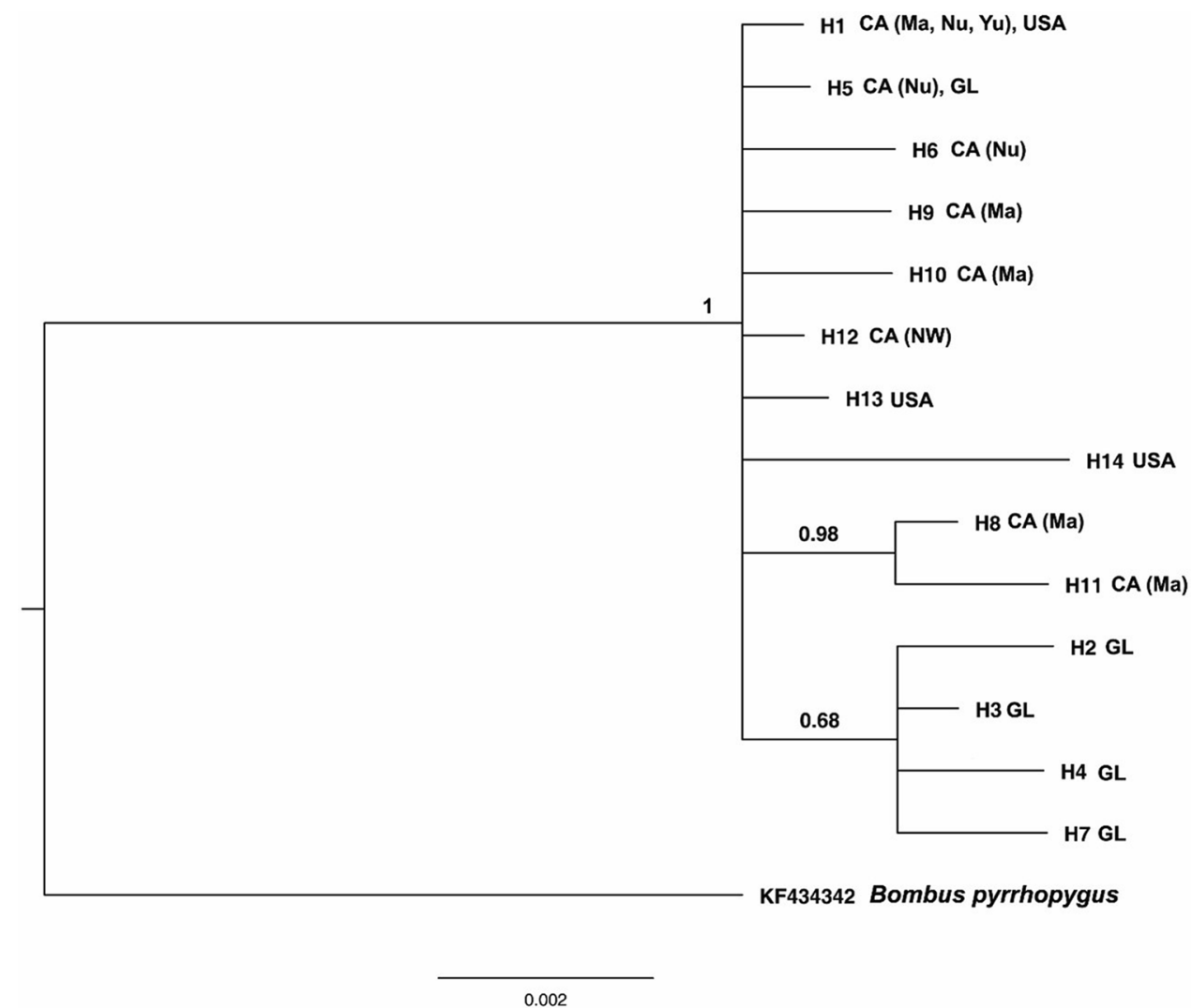




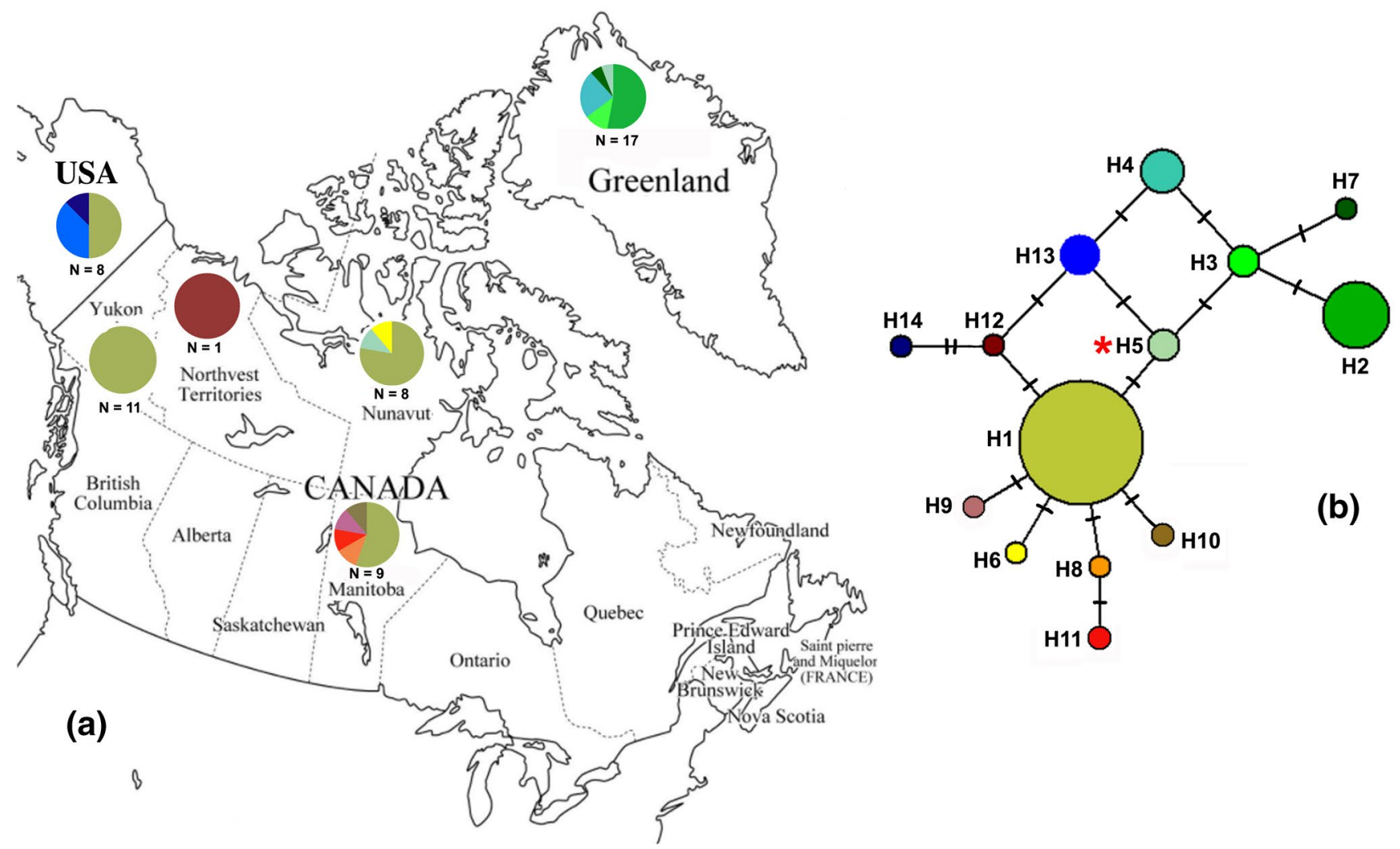

Fig. 4 a Geographical distribution of haplotype frequencies of the COI gene in Bombus polaris. Pie charts indicate the frequency of haplotypes within each population. Each circle corresponds to a locality. Haplotypes found are indicated by different colours. b Median-joining haplotype network for 654-bp fragment of the COI

Greenland produced a star-shape structure with $\mathrm{H} 3$ in the centre; however, this haplotype was not the most abundant haplotype in Greenland (Fig. 4).

\section{Discussion}

\section{Relationships to other B. polaris populations}

The phylogenetic tree and haplotype network both indicate a close relationship between the Canadian and Greenland populations. The newly collected specimen from North Greenland shared the same haplotype (H5) with a sequence from North Canada (Nunavut) and was closely related to the H1, a common haplotype in Canada (Nunavut, Manitoba and Yukon), connecting the more divergent haplotypes from even Eastern Greenland to the Canadian populations. In spite of the presence of some geographical barriers such as Baffin Bay and the Labrador Sea, Greenland is quite close to Canada geographically and part of the Nearctic biogeographic realm. Furthermore, B. polaris has earlier been reported from Ellesmere Island (Kevan 1972) $500 \mathrm{~km}$ to the west of gene of the B. polaris. Each circle represents one haplotype. The numbers under each circle indicate total haplotypes. The size of the haplotypes is drawn proportionately to their frequencies and the new haplotype 5 is marked with an asterisk next to it

the place in North Greenland where our specimen was collected. Therefore, our finding of a close genetic relationship between Canadian and Greenland B. polaris individuals does not come as a total surprise.

It is well known that migratory birds flying from northern Canada to north-east Greenland and western Iceland are aided by weather conditions and often fly across North Greenland. Although we cannot say since when B. polaris and $B$. hyperboreus have been occurring in North Greenland and we can probably rule out passive transport as hitchhikers on, for example, migratory Brent Geese (Branta bernicla hrota), it does seem possible that winds from Canada could have aided bumble bees in colonizing northern and north-eastern Greenland from the West. Mass migrations of bumble bees have indeed been reported by Fijen (2021), who even suggested that the recent colonization of Iceland by several continental European bumble bee species (Potapov et al. 2018b) could have been the consequence of migrating queens from continental Europe, aided by wind and warmer climatic conditions. On the other hand, an anthropogenic introduction (another suggestion for the presence of European mainland Bombus species in Iceland: Prys-Jones et al. 
2016) can certainly be ruled out for North Greenland's bumble bee populations as native Greenlanders had little if any use for bumble bees and never settled in North Greenland.

Although our knowledge about the level of genetic diversity in B. polaris populations is limited, finding five haplotypes in 17 studied sequences does indicate a moderately high level of genetic diversity of B. polaris in Greenland. This conclusion of ours is supported by results on different European populations of B. terrestris (Linnaeus 1758) and B. pascuorum (Scopoli 1763) that resulted in only four and five haplotypes, respectively (Estoup et al. 1996; Pirounakis et al. 1998). Takeuchi et al. (2019) also reported low genetic variation amongst populations of the endangered species $B$. cryptarum florilegus (Panfilov 1956) in Japan (only one haplotype in each of the three populations studied). On the other hand, six haplotypes were found in an analysis of 13 sequences of Arctic bumblebee B. hyperboreus natvigi in all its distributional territories, namely three haplotypes in six sequences examined from Greenland (Potapov et al. 2019). The level of genetic diversity plays an important role in the successful adaptation of a population to adverse and uncertain environmental conditions such as a changing climate (Kawecki and Ebert 2004). Failure of adaptation due to low genetic diversity could lead to extinction; therefore, having some information on the genetic diversity and geographic relationships of a population is crucial for decisions on the conservation of a species, especially if we are dealing with an important pollinator (Goulson et al. 2008; Zayed 2009; Habel et al. 2014).

\section{Distribution and survival of Arctic bumble bees}

Bumble bee survival and occurrence depends on the availability of pollen and nectar sources and summer as well as winter temperature extremes (Potapov et al. 2019). In this regard, Arctic species, generally, show similarities to cold-adapted, high-altitude species of the Himalayas (Streinzer et al. 2019). The causality of the species abundance in such extreme habitats, however, was not studied in connection with the Himalayan species, but it was the subject of a study in connection with Arctic species. Williams et al. (2015) pointed out that speciation is likely to have cut across widespread ancestral polymorphisms and was affected by allopatrically separate populations prevented from interbreeding by barriers like, e.g. oceans and mountain ridges. An important environmental parameter, however, is also the much greater UV-irradiation at a highaltitude, low-latitude environment than the UV, which prevails at a high latitude and low altitude, the latter a situation influenced additionally by the amount of cloud cover that organisms would encounter in North Greenland (Blumthaler et al. 1997; Meyer-Rochow 2000).
The dearth of UV-radiation in the far north could possibly affect the way the bumble bees under debate detect their pollen sources. Bumble bees, like bees generally and like the sub-polar northern Finnish species of B. hortorum (Linnaeus 1761), studied in detail by Meyer-Rochow (1981), possess specific photoreceptive cells in their eyes with maximum sensitivity to light of around $360 \mathrm{~nm}$ wavelength, i.e. UV-A radiation. The bees respond to the UV component of the light that is reflected by the inflorescences that they seek to obtain pollen and nectar from and, as shown by Kevan (1972), B. polaris plays a major role as a pollinator of high-Arctic flowers, especially those of the abundant Pedicularis spp., Salix arctica (Pallas 1788) and Ericaceae of the region. Other plants with a northern distribution like Stylophorum sp. and crowberries can be considered pollen and nectar providers, respectively, and are likely to be also visited by $B$. polaris, although direct observations have not been reported.

Whether the northernmost stands of these flowering plants possess stronger UV-signals on their petals to compensate for the weaker UV-radiation at high latitudes (as has been reported for the wings of sexually dimorphic subArctic Pieris napi (Linnaeus 1758) butterflies by MeyerRochow and Järvilehto 1997 as well as Stella et al. 2018) or high-Arctic bumble bees possess a superior sensitivity to the available lower UV remains to be investigated. Given that differences in photoreceptor spectral sensitivities have been recorded in island and mainland populations of the Italian B. terrestris by Skorupski et al. (2007), it would not be surprising to find similar differences in different populations of Arctic bumble bee species.

\section{And in the future...}

To explore the extent that global warming might have in affecting the distribution of bumble bees adapted to the cold environments of Arctic and alpine biomes, Lee et al. (2019) have recently carried out predictive analyses based on five climate variables. According to their results, the Arctic bumble bees are in greater danger of being adversely affected by the climate change than the alpine species and the former would be "required to disperse across larger distances than [the] alpine species" to avoid becoming extinct. A great deal, however, depends on how the pollen and nectar sources of the high Arctic would respond to global warming and whether the bumble bees of the high Arctic would accept other pollen and nectar sources than those that they are currently accustomed to. However, this is just one more aspect in connection with high-Arctic bumble bees that still needs to be investigated. 
Supplementary Information The online version contains supplementary material available at https://doi.org/10.1007/s00300-021-02952-y.

Acknowledgements VBM-R and SMN are grateful for the support that the project had received from Professor Chuleui Jung via the Basic Science Research Program of the National Research Foundation of Korea (NRF), funded by the Ministry of Education (NRF2018R1A6A1A03024862). We wish to thank Dr Won Young Lee for having made his specimen of $B$. polaris available for this study. TYP's work in Greenland was supported by KOPRI project PE21060 and the photographs of $B$. polaris in this paper were taken by Gert Brovad, Natural History Museum of Denmark. The weather data of Sirius Passet were acquired by an Automatic Weather Station (AWS) manufactured by Ju-Han Lee (KOPRI) and set up by Young Keun Jin and Cheon-Yun Kang (AWS). We thank Dr Lars Vilhelmsen and two other anonymous reviewers for very helpful and insightful comments and suggestions to improve this paper.

Author contributions SMN performed the molecular analyses, interpreted the data and located some key publications. VBM-R suggested the study, wrote the first draft of the manuscript and its last version, located key publications and contributed information on biology and ecology of Arctic bumble bees. TYP was responsible for the expedition to North Greenland and provided weather data and CJ made laboratory facilities and analytical equipment available.

Funding Open access funding provided by University of Oulu including Oulu University Hospital. The research received support from a grant to Professor Chuleui Jung via the Basic Science Research Program of the National Research Foundation of Korea (NRF), funded by the Ministry of Education (NRF-2018R1A6A1A03024862).

\section{Declarations}

Competing interests The authors declare they have no competing interests.

Ethical approval The research has been conducted under permission from the Greenland government, and the permits include consideration and approval (permission no. G16-074, C-17-4). The local ethics committee (Ministry of Industry and Mineral Resources, the Government of Greenland) specifically reviewed and approved the application for survey license on the use of biological resources for commercial and research purposes (in the: "Act on Biological Resources").

Informed consent All four authors agreed to participate.

Open Access This article is licensed under a Creative Commons Attribution 4.0 International License, which permits use, sharing, adaptation, distribution and reproduction in any medium or format, as long as you give appropriate credit to the original author(s) and the source, provide a link to the Creative Commons licence, and indicate if changes were made. The images or other third party material in this article are included in the article's Creative Commons licence, unless indicated otherwise in a credit line to the material. If material is not included in the article's Creative Commons licence and your intended use is not permitted by statutory regulation or exceeds the permitted use, you will need to obtain permission directly from the copyright holder. To view a copy of this licence, visit http://creativecommons.org/licenses/by/4.0/.

\section{References}

Bandelt HJ, Forster P, Röhl A (1999) Median-joining networks for inferring intraspecific phylogenies. Mol Biol Evol 16:37-48

Blumthaler M, Ambach W, Ellinger R (1997) Increase in solar UV radiation with altitude. J Photochem Photobiol B 39:I30-I34

Boertmann D, Mosbech A, Frimer O (1997) Autumn migration of light-bellied Brent Geese Branta bernicla hrota through northwest Greenland. Wildfowl 48:98-107

Born EW, Böcher J (2001) The ecology of Greenland. Ministry of Environment and Natural Resources in Nuuk, Greenland, p 429

Couvillon MJ, Fitzpatrick G, Dornhaus A (2010) Ambient temperature does not predict whether small or large workers forage in bumble bees (Bombus impatiens). Psyche (London), [536430]. https://doi. org/10.1155/2010/536430

Darriba D, Taboada GL, Doallo R, Posada D (2012) J Model Test 2: more models, new heuristics and parallel computing. Nat Methods 9(8):772

Estoup A, Solignac M, Cornuet M, Goudet J, Scholl A (1996) Genetic differentiation of continental and island populations of Bombus terrestris (Hymenoptera: Apidae) in Europe. Mol Ecol 5(1):19-31

Folmer O, Black M, Hoeh W, Lutz R, Vrijenhoek R (1994) DNA primers for amplification of mitochondrial cytochrome $\mathrm{c}$ oxidase subunit I from diverse metazoan invertebrates. Mol Mar Biol Biotechnol 3:294-299

Goulson D, Lye GC, Darvill B (2008) Decline and conservation of bumble bees. Annu Rev Entomol 53:191-208

Habel JC, Husemann M, Finger A, Danley PD, Zachos FE (2014) The relevance of time series in molecular ecology and conservation biology. Biol Rev 89:484-492

Hall TA (1999) BioEdit: a user-friendly biological sequence alignment editor and analysis program for Window 95/98/NT. Nucleic Acids Symp Ser 41:95-98

Hatfield R, Jepsen S, Thorp RW, Richardson L, Colla S, Foltz-Jordan S (2016) Bombus polaris. The IUCN Red List of Threatened Species 2016

Huelsenbeck JP, Ronquist F (2011) MRBAYES: Bayesian inference of phylogeny. Bioinformatics 17:754-755

Fijen TPM (2021) Mass-migrating bumblebees: an overlooked phenomenon with potential far-reaching implications for bumblebee conservation. J Appl Ecol 58:274-280

Kawecki TJ, Ebert P (2004) Conceptual issues in local adaptation. Ecol Lett 7:1225-1241

Kevan PG (1972) Insect pollination of high Arctic flowers. J Ecol 60(3):831-847

Kolosova YS, Potapov GS, Skyutte NG, Bolotov IN (2016) Bumblebee (Hymenoptera, Apidae, Bombus Latr.) of the thermal spring Pymvashor, north-east of European Russia. Entomol Fennica 27:190-196

Lee CKF, Williams PH, Pearson RG (2019) Climate change vulnerability higher in Arctic than alpine bumblebees. Front Biogeogr 11(4), e42455

Librado P, Rozas J (2009) DnaSP v5: software for comprehensive analysis of DNA polymorphism data. Bioinformatics 25:1451-1452

Martinet B, Brasero N, Lecocq T, Biella P, Valterova I, Michez D, Rasmont $\mathrm{P}$ (2018) Adding attractive semio-chemical trait refines the taxonomy of Alpinobombus (Hymenoptera: Apidae). Apidologie 49:838-851

Meyer-Rochow VB (1981) Electrophysiology and histology of the eye of the bumblebee Bombus hortorum (L.) (Hymenoptera: Apidae). J R Soc N Zld 11(s): 123-153

Meyer-Rochow VB (2000) Risks, especially for the eye, emanating from the rise of solar UV-radiation in the Arctic and Antarctic regions. Int J Circumpolar Health 59:38-51 
Meyer-Rochow VB, Järvilehto M (1997) Ultraviolet colours in Pieris napi from northern and southern Finland: Arctic females are the brightest! Naturwissenschaften 84:165-168

Parrey AH, Raina RH, Saddam B, Pathak P, Kumar S, Uniyal VP, Gupta D, Khan SA (2021) Role of bumblebees (Hymenoptera: Apidae) in pollination of high land ecosystem: a review. Agricult Rev https://doi.org/10.18805/ag.R-2159

Pirounakis K, Koulianus S, Schmid-Hempel P (1998) Genetic variation among European populations of Bombus pascuorum (Hymenoptera: Apidae) from mitochondrial DNA sequence data. Eur J Entomol 95(1):27-33

Potapov GS, Kolosova YS, Gofarov MY (2014) Zonal distribution of bumblebee species (Hymenoptera, Apidae) in the North of European Russia. Zool Zhurnal 92(10):1246-1252

Potapov GS, Kondakov AV, SpitsynVM FBY, Kolosova YS, Zubrii NA, Bolotov IN (2018a) An integrative taxonomic approach confirms the valid status of Bombus glacialis, an endemic bumblebee species of the High Arctic. Polar Biol 41:629-642

Potapov GS, Kondakov AV, Kolosova YS, Tomilova AA, Filippov BY, Gofarov MY, Bolotov IN (2018b) Widespred continental mtDNA lineages prevail in the bumblebee fauna of Iceland. Zookeys 774:141-153

Potapov GS, Kondakov AV, Filippov BY, Gofarov MY, Kolosova YS, Spitsyn VM, Tomilova AA, Zubrii NA, Bolotov IN (2019) Pollinators on the polar edge of the Ecumene: taxonomy, phylogeography, and ecology of bumble bees from Novaya Zemlya. Zookeys $866: 85-125$

Potapov GS, Berezin MV, Kolosova YS, Kondakov AV, Tomilova AA, Spitsyn VM, Zheludkova AA, Zubrii NA, Filippov BY, Bolotov IN (2021) The last refugia for a polar relict pollinator: isolates of Bombus glacialis on Novaya Zemlya and Wrangel Island indicate its broader former range in the Pleistocene. Polar Biol. https://doi. org/10.1007/s00300-021-02912-6

Prys-Jones O, Kristjánsson K, Ólafsson E (2016) Hitchhiking with the Vikings? The anthropogenic bumblebee fauna of Iceland-past and present. J Nat Hist 50(45/46):2895-2916

Rasmont P, Iserbyt I (2010-2014) Atlas of the European Bees: genus Bombus. 3d Edition. STEP Project, Atlas Hymenoptera, Mons, Gembloux. http://www.atlashymenoptera.net/page.aspx?ID=169

Richards KW (1973) Biology of Bombus polaris Curtis and B. hyperboreus Schönherr at Lake Hazen, Northwest Territories (Hymenoptera, Bombini). Quaest Entomologicae 9(2): 115-158

Sheffield CS, Oram R, Heron JM (2020) Bombus (Pyrobombus) johanseni Sladen, 1919; a valid North American bumble bee species, with a new synonymy and comparisons to other "redbanded" bumble bee species of North America (Hymenoptera, Apidae, Bombini). Zookeys 984:59-81
Skorupski P, Döring TF, Chittka L (2007) Photoreceptor spectral sensitivity in island and mainland populations of the bumblebee Bombus terrestris. J Comp Physiol A 193:485-494

Stella D, Pecháček P, Meyer-Rochow VB, Kleisner K (2018) UVreflectance is associated with environmental conditions in Palaearctic Pieris napi (Lepidoptera: Pieridae). Insect Sci 25:508-518

Streinzer M, Chakravorty J, Neumayer J, Megu K, NarahJ ST, Bharti H, Spaethe J, Brockmann A (2019) Species composition and elevational distribution of bumble bees (Hymenoptera, Apidae, Bombus Latreille) in the East Himalaya, Arunachal Pradesh, India. Zookeys 851:71-89

Takeuchi T, Sasaki T, Mitsuhata M, Kiyoshi T, Nishimoto M, Nomura T, Takahasi J (2019) Low mitochondrial DNA variation in the endangered bumble bee Bombus cryptarum florilegus. J Apicult Res 58(4):591-596. https://doi.org/10.1080/00218839.2019. 1614735

Thomas DN (2021) Arctic ecology. Wiley Blackwell, Hoboken

Thompson JD, Higgins DG, Gibson TJ (1994) Clustal W: improving the sensitivity of progressive multiple sequence alignment through sequence weighting position-specific gap penalties and weight matrix choice. Nucleic Acids Res 22:4673-4680

Vilhelmsen L (2015) Apidae (Apoidea) (Bees). In: J Böcher, NP Kristensen, T Pape, L Vilhelmsen (eds) Vol 44, The Greenland entomofauna - an identification manual of insects, spiders and their allies. Brill, Leiden (The Netherlands), pp 254-257. ISBN: 978-90-04-26105-1

Wahengam J, Raut AM, Satinder P, Banu N (2019) Role of bumble bee in pollination. Ann Biol 35(2):290-295

Williams PH, Byvaltsev AM, Cederberg B, Berezin MV, Ødegaard F, Rasmussen C et al (2015) Genes suggest ancestral colour polymorphisms are shared across morphologically cryptic species in Arctic bumblebees. PLoS ONE 10:1-26

Williams PH, Berezin MV, Cannings SG, Cederberg B, Ødegaard F, Rasmussen C et al (2019) The Arctic and alpine bumblebees of the subgenus Alpinobombus revised from integrative assessment of species' gene coalescents and morphology (Hymenoptera, Apidae, Bombus). Zootaxa 4625(1):1-68

Zayed A (2009) Bee genetics and conservation. Apidologie 40:237-262

Publisher's Note Springer Nature remains neutral with regard to jurisdictional claims in published maps and institutional affiliations. 